\title{
ON-FARM TESTING OF FEED TECHNOLOGIES FOR IMPROVED SMALLHOLDER DAIRY PRODUCTION IN VIHIGA DISTRICT OF WESTERN KENYA
}

\author{
E.A. Mukisira and K.O. Otieno
}

Kenya Agricultural Research Institute, P.O. Box 57811, Nairobi

\section{SUMMARY}

In a topical Participatory Rural Appraisal (PRA) study, dairying was identified as a potential source of income and milk for families in Vihiga District, western Kenya. Ex-ante constraint identification as validated from the PRA studies indicated that dairy feed scarcity, particularly during the dry season, is a priority constraint. The common forages used by farmers do not provide sufficient feed to fully exploit the genetic potential of dairy cattle kept, leading to low milk production and consequently a diminished income base. Constraints and gender analyses done during the PRA tended to favour research interventions that would allow for the exploitation of Napier grass (Pennisetum purpureum), crop residues and molasses as a sustainable alternative to enhancing feed availability on smallholder farms in the targeted farms. It is on the basis of these PRA results that an on-farm research was subsequently planned and executed with the full participation of farmers, researchers and extensionists. Among the technologies focused on were the practicability of improving the quality of crop residues and the efficiency of utilizing them on-farm. Primarily the research focused on improving and efficiently utilizing the abundant maize stover, mostly during the dry season. Besides, demands from the farmers on issues of maize stover storage for dry season feeding were concurrently addressed. Secondarily, there were adaptive trials on various forages on a few selected farms. The research targeted farmers within the maize, bananas, tea, coffee, dairy land-use production system where, although tea is the main cash crop, the dairy enterprise is increasingly becoming an integral component of the farming system. The on-farm feeding trials involved 24 farmers ( 15 males and 9 females) and was carried out between 1998 and 1999 within Sabatia, Emuhaya and Luanda Divisions of Vihiga District. Nine additional farmers ( 4 women and 5 men) were involved in the forage demonstration trials within the study area. Results indicate a real potential for improving feed availability on small holder farms and a concomitant increase in milk yield and farmer income. These results are discussed with consideration to gender, methodology, technology transfer and adoption, and potential impact.

\section{Keywords: Feed technology, dairy production, small farmers, on farm trials, Kenya}

\section{INTRODUCTION}

The dairy cattle enterprise is an integral component of most smallholder farms in Kenya contributing over $80 \%$ of the total milk produced (NDDP, 1990). Although dairying is a promising enterprise for smallholder farmers in western Kenya, current production data reveals that the production per unit cow is low. This is attributed to the small landholdings coupled with the fact that a significant proportion of the land area is allocated to food and cash crops. In a similar observation in the Central highlands of Kenya, Abate et al. (1987) attributed this poor performance of dairy cows to nutritional problems in terms of quality and quantity of feed. Indeed, the situation in Vihiga District is such that the increasing human population has created pressure on available land with a greater proportion of it cultivated to grow food and cash crops thereby marginalizing the area under forages. The dairy production system in the study area is zero-grazing ; a system in which animals are fed in confinement mainly on 'cut' and 'carry' Napier grass (Pennisetum purpureum). Land holdings per household, however, limit the amount of Napier grass that can be grown by smallholder dairy farmers.

The inability to feed animals adequately throughout the year is the most widespread technical constraint facing dairy farmers within the targeted area. During the dry season, the quantity of feed is the major limiting factor to dairy production. Napier grass, the main forage source for dairy cattle should be capable of sustaining milk yields of $7 \mathrm{~kg} /$ day, but production is lowered by the decline in quality of Napier grass during the dry season and the inappropriate feeding of lower quality feeds such as maize stover. The inevitable result is that dairy production remains low in the region leading to a loss in overall farm productivity and subsequently to a low income base for the small holder dairy farmers. The project attempted to "test" on-farm appropriate technologies that could reverse this situation. Options that would sustain increased feed resources by optimising the use of local resources were tested to improve dairy production within the targeted areas. 
Renard ( 1997) noted that in tropical rainfed agriculture in Africa, cattle obtained between 16 and $40 \%$ of their DM intake from crop residues. The proportion rises to 50 and $80 \%$ during the dry season, when few alternative feeds are available. In the targeted area for this study, farmers rely on crop residues of all types during the dry season although, it is generally accepted that these have poor chemical composition and consequently low nutritive value (Kevelenge, 1978; MacMillan, 1996). Small-scale dairy farmers in Vihiga District use crop residues derived from maize, banana pseudostems and leaves, bean hauls, sweet potato vines as supplementary sources of feeds, particularly during the dry season. Maize is the main staple food crop that is grown by farmers in several parts of Kenya; its distribution in Vihiga District is equally wide and the proportion of land allocated to maize is generally higher than for other crops. The national importance of maize stover is underscored by the fact that $7.5 \mathrm{~m}$ tons are produced yearly in Kenya (Abate et al., 1992). In Central Kenya, the importance of maize stover as a major component of feed to dairy cattle has clearly been demonstrated (Methu et al. 1997). In the present study, appropriate technological options that lead to a greater and improved usage of maize crop residues were considered a priority for dairy production and needed to be "tested" with the full participation of farmers. One novel research approach contemplated was the improvement of stover quality by the addition of molasses and stock salt. Incorporation of this mixture in Napier grass offered the "best" bet in addressing the feed supply situation, especially during the dry season.

This project was formulated with the broad objective of developing appropriate strategies for efficient utilization of the available feedstuffs to improve milk production on small holder farms in Vihiga District. Primarily, it was to test on-farm feed technologies for improved smallholder dairy production in three target Divisions of Vihiga District. Initially, 'test' diets were composed of Napier grass (fresh or ensiled) mixed with homegrown or commercial supplements. A topical PRA conducted prior to the study revealed that there were inadequate quantities of Napier grass on-farm, particularly during the dry season, for the intended studies. The re-formulation of the trials was necessary to incorporate farmer perspectives towards a sustainable approach of feeding Napier grass along with forage legumes and crop residues; the latter was improved on by adding molasses and stock salt. Although maize stover is the most abundant crop residue in the targeted area, no adequate information was available on its efficient use by farmers as livestock feed. Additionally there was no information on attempts by farmers to improve its quality for increased animal performance.

The study objectives were to:

- Test existing feed technologies "on the shelf" for dairy cattle feeding on selected smallholder farms in Vihiga District

- Assist farmers establish suitable forages on their farms

- Train farmers on the agronomic and feed aspects of the locally available feed resources

- Perform an economic assessment of the promising feed technologies

- Disseminate information on proven feed technologies for dairy production to smallholder farmers in the target area through seminars, workshops and extension leaflets.

The average annual rainfall is $1900 \mathrm{~mm}$ with the long rains occurring from March to June. Dry spells occur in December to February. The District has undulating hills with some areas having rock outcrops bisected by deep river valleys and numerous perennial streams. Soils range from well drained loams to red clays. Naturally soil fertility has been depleted by intensive cropping without replenishing the soils with organic and inorganic fertilizers. The farming system of the area is predominantly mixed farming. Tea is the main cash crop but over $85 \%$ of the farmers grow other crops mainly for subsistence use, the most important being maize. Dairying is an integral component of the farming systems and was highly rated by the farmers as a potential source of regular income and manure. However, most farmers keep zebu or crossbreds which are tethered within the homesteads. The forages are often grown on terraces or on the edges of cultivated crop fields. The main forage being grown is Napier grass. Inadequate feeding of dairy cattle due to feed scarcity is a major constraint to smallscale farmers who rear pure grade cattle; this was the main target group for this project.

\section{MATERIALS AND METHODS}

\section{Study Site Description}

The project operated from the Kenya Agricultural Research Institute (KARI), Regional Research Centre (RRC) at Kakamega, which is mandated to conduct research in the present study locations. The on-farm trial targeted smallholder dairy farmers, with land holdings averaging 0.4 ha, within the maize, tea, coffee, dairy 
land-use production system in Sabatia, Luanda and Emuhaya Divisions of Vihiga District. Vihiga District has one of the highest population densities in Kenya (approximately 700 persons per $\mathrm{km}^{2}$ ).

\section{Experimental Approach}

A collaborative approach was applied in which researchers, extensionists and farmers were actively involved in all the stages of the research process viz:: problem diagnosis or identification, testing and the evaluation of the technologies, monitoring and evaluation, and the dissemination of already proven components of technologies. The following are the major activities that were involved at each stage:-

\section{Problem Diagnosis and Development of Research Agenda}

The project formulation started with the collection of general information on dairy development within a broader area focusing more on the general production constraints. The source of the information included informal/formal contacts by researchers and extensionists with farmers, and on secondary information from reports and surveys. A technical report on the findings of a topical PRA was produced and circulated to the research team. The PRA initiative further suggested to the research team a number of socio-cultural criteria that required monitoring during the study. The project sites were then identified from which more research impact would be expected after considering the level of dairy development and the perceived priority.

\section{Farmer Selection}

Selection of farmers to participate in the on-farm activities was done by carrying out extensive interviews with individual farmers. Initially farmer interviews were conducted on a large number of farms. The objective was to obtain farmer perceptions and opinion over the proposed project and potential interventions. Overall, farmers were selected on the basis of their active participation in dairy farming, interest and willingness to participate in the on-farm research. In addition, selected farmers were to appreciate the role of maize crop residues in the feeding of dairy cattle and, at least, own a lactating dairy cow at the onset of the on-farm feeding trial. Based on the information gathered, a total of 24 farmers comprising of 15 males and 9 females were finally selected in July-August, 1998 to test the available technological options. These set of farmers were involved in on-farm feed trials to determine the performance of lactating cows fed on Napier grass-maize stover-molasses based diets. An additional 8 farmers were selected in February, 1999 for on-farm demonstration trials on the establishment and management of fodders thus Napier grass (cv. Bana, Pakistan hybrid and French Cameroon) and legumes i.e desmodium.

\subsection{Planning Meetings}

Planning meetings/workshop were held before the commencement of each research activity during which researchers, extensionists and more importantly, the selected farmers deliberated on the prototype technologies proposed by the researchers. The proposed technologies mainly focused on the:-

- improvement and the utilisation of crop residues for dairy cattle feeding

- post-harvest management of mostly maize stover

- appropriate fodder establishment and management techniques.

A number of meetings were held where these technologies were presented to farmers and open-ended discussion encouraged to allow for critique and suggestions considering their responsiveness to addressing the feed problem and the socio-economic circumstances. Besides, these meetings provided for a systematic collection of farmers' perceptions and reactions, from both individual and groups of farmers. The meetings also provided an opportunity for views and opinions of non-participating farmers, neighbours and visitors from other villages to farmers in whose fields technologies were actually tested.

It was also during the planning meetings that an assessment was made on the practicability of the experimental protocol presented by researchers, and on the participatory roles in the management and monitoring of the trials. Emphasis here was placed on joint ownership of the technologies from the designing phase to the actual implementation on the farms.

\section{On-farm Experimentation and Monitoring}

Once the interventions were agreed upon during the planning meetings, on-farm studies commenced within the selected farms. Preliminary visits were made by the research and extension staff to prepare the farmer for the on-farm research activities. For each of the experimental site, the participating and a few nonparticipating farmers were invited for demonstrations on how to formulate rations involving Napier grass, maize stover, molasses, stock salt and other locally available feed stuffs. In addition, several training 
workshops were held for the front-line extension staff in the target area. Farmers were encouraged to use the local measures when mixing the respective individual components of the rations.

\section{Diets and Experimental Animals}

The main ingredients of diets formulated for the on-farm trials were chopped fresh Napier grass, molasses and maize stover. The farmer could modify the diets by adding other ingredients available at his/her farm. A few farmers, particularly those who had adequate quantities of Napier grass and maize stover decided not to alter the diet significantly. The 24 cows selected for these trials were mostly grade or crosses in their $2^{\text {nd }}$ to $4^{\text {th }}$ lactation stages, from 70 to 150 days post-partum. On-farm feeding trials were initiated in December, 1998 and ended in February, 1999. From what farmers fed, and with the technical guidance of the research team, 4 diets emerged (Table 1).

\section{Table 1. Physical composition of diets fed to lactating cows by test farmers}

\begin{tabular}{clc}
\hline Diet & Composition & $\begin{array}{c}\text { No. of } \\
\text { farmers* }\end{array}$ \\
\hline A & Napier grass+Maize stover+ molasses + salt +banana stems/leaves+ Sweet potat & 7 \\
& vines (SPV) & 3 \\
B & Napier grass+Maize stover+ molasses + salt + calliandra leaves & 6 \\
C & Napier grass+Maize stover+ molasses + salt +dairy meal & 8 \\
D & Napier grass+Maize stover+ molasses + salt & \\
\hline
\end{tabular}

* Total number of experimental farmers were 24

Each farmer had 1 lactating cow on trial

The rationale was to determine the changes in milk production after cows were fed these "test" diets. Each of the prescribed diets in each experiment was offered for a preliminary period of 14 days followed by a collection period of approximately 60 days. Initial milk production levels of the cows prior to the preliminary period, although not accurately established, were sourced from the farmers. During the experimental period, records on daily milk yields and daily intakes were recorded by the farmer using spring balances provided by the project. Farmers not participating in the feeding experiments were encouraged to visit experimental farmers in their locality so that they can gather some knowledge on the efficient utilization of maize stover mostly during the dry season. It was envisaged that these visits would enhance wider adoption of the technologies through "farmer to farmer' diffusion.

\section{Participatory Evaluation of Technologies}

After completion of each on-farm activity, farmers involved in each research undertaking, were invited. for a review meeting to capture feedback information on the feeding trial conducted at the three experimental sites. The research team also noted the farmer's comments/perceptions regarding the trials. These feedback sessions guided the researcher as to the possible adoption and impact of the technologies.

\section{RESULTS AND DISCUSSION}

\section{Experimental Diets and Feeding}

The composition of the 4 diets, as preferred by the farmers, is indicated in Table 2 . All the diets consisted of chopped fresh Napier grass, chopped maize stover, molasses and stock salt. However, the four diets contained varying proportions of these ingredients besides the additional feedstuffs incorporated by the farmers. Though the project availed a simple spring balance to participating farmers for determining accurate quantities of the dietary ingredients and for weighing refusals and milk yields, the use of local measures was encouraged since most farmers in the locality were familiar with them.

Table 2. Ingredient composition ( $\mathrm{kg}$ ) of diets fed during the on-farm feeding trials

\begin{tabular}{lll}
\hline Diet A & $\begin{array}{l}\text { Amount offered }(\mathrm{kg}) \\
\text {-as is (cow/day) }\end{array}$ & $\begin{array}{l}\text { Local measure } \\
\text { "by volume" }\end{array}$ \\
\hline Chopped Napier grass & 15.5 & 1 "gunny bag" $(70 \mathrm{~kg})$ \\
Chopped maize stover & 9 & 1.5 "gunny bag" $(70 \mathrm{~kg})$ \\
Chopped banana stems/leaves & 7 & $1 / 3$ "fertilizer bag" $(50 \mathrm{~kg})$ \\
Chopped sweet potato vines & 1 & 1 'gorogoro'* (packed) \\
Stock salt & 0.25 & 1 cup (size 8$)$ \\
Molasses & 2 & 1 "gorogoro" \\
\hline
\end{tabular}


Table 2 (Contd')

\begin{tabular}{lll}
\hline Diet B & $\begin{array}{l}\text { Amount offered }(\mathrm{kg}) \\
\text {-as is (cow/day) }\end{array}$ & $\begin{array}{l}\text { Local measure } \\
\text { "by volume" }\end{array}$ \\
\hline Chopped Napier grass & 16.5 & 1 "gunny bag" $(70 \mathrm{~kg})$ \\
Chopped maize stover & 9 & 1.5 "gunny bag" $(70 \mathrm{~kg})$ \\
Calliandra leaves & 7 & 1 calendar type plastic bag \\
Stock salt & 0.25 & I cup (size 8) \\
Molasses & 2 & 1 "gorogoro" \\
\hline & & \\
\hline Diet C & Amount offered $(\mathrm{kg})$ & Local measure \\
& - as is (cow/day) & "by volume" \\
\hline Chopped Napier grass & 15.5 & 1 "gunny bag" $(70 \mathrm{~kg})$ \\
Chopped maize stover & 9 & 1.5 "gunny bag" $(70 \mathrm{~kg})$ \\
Dairy meal & 4 & 4 "gorogoros" \\
Stock salt & 0.25 & 1 cup (size 8$)$ \\
Molasses & 2 & 1 "gorogoro" \\
\hline & & \\
\hline Diet D & Amount offered (kg) & Local measure \\
& - as is (cow/day) & "by volume" \\
\hline Chopped Napier grass & 18 & 1.25 "gunny bag" $(70 \mathrm{~kg})$ \\
Chopped maize stover & 9 & 1.5 "gunny bag" $(70 \mathrm{~kg})$ \\
Stock salt & 0.25 & 1 cup (size 8$)$ \\
Molasses & 2 & 1 "gorogoro" \\
\hline
\end{tabular}

*a volume measure equivalent to $2 \mathrm{~kg}$ "kimbo" tin

all diets were composted to provide $12-15 \mathrm{~kg} \mathrm{DM}$

\section{Animal Performance}

The results for the feeding trial undertaken during the dry season of December, 1998 to February, 1999 are presented in Table 3. The small number of cows involved in the trial precluded the detection of significant dietary effects. There was, however, a response by cows to the diets provided, as indicated by the slight increases in milk yield relative to those realized during the pre-experimental period.

Table 3. Diet Intakes $\left(\mathrm{kg} \cdot \operatorname{cow}^{-1} \cdot \mathrm{d}^{-1}\right)$ and milk yield $\left(\mathrm{kg} \cdot \operatorname{cow}^{-1} \cdot \mathrm{d}^{-1}\right)$ of lactating dairy cows

\begin{tabular}{lllll}
\hline Item & \multicolumn{4}{l}{ Diet } \\
\cline { 2 - 5 } & $\mathrm{A}$ & $\mathrm{B}$ & $\mathrm{C}$ & $\mathrm{D}$ \\
\hline Pre-expt. milk yield & $4.7(1.23)$ & $3.2(0.39)$ & $5.0(3.08)$ & $4.3(1.37)$ \\
During expt milk yield & $5.9(1.35)$ & $4.1(0.67)$ & $6.3(3.08)$ & $5.54(1.96)$ \\
Changes in milk yield & $1.2(0.29)$ & $0.9(1.02)$ & $1.24(0.79)$ & $1.22(0.69)$ \\
Intake (as is basis) & $37.2(7.64)$ & $24.9(3.19)$ & $57.3(18.48)$ & $15.5(34.8)$ \\
\hline
\end{tabular}

( ) values in brackets represent sample standard deviations

The average daily milk production indicated that cows fed the 4 diets demonstrated slight yield increases in milk over the production realized in the pre-experimental period. The milk yield increases were $1.2,0.9,1.24,1.22 \mathrm{~kg} \cdot \operatorname{cow}^{-1} . \mathrm{d}^{-1}$ for cows fed diets $A, B, C$ and $D$, respectively. However, these increases were not significantly different from those attained in the pre-treatment period, possibly due to the high variability in the data collected on-farm. Interestingly, the cows fed diet $D$, which was composted from only a mixture of Napier grass, chopped maize stover and molasses, still demonstrated improved milk yields. It should be recognized that breed differences, the quantity of feed, the variability in the chemical composition of the diets, the stage of lactation, the actual dry matter consumed by the cows could have confounded the dietary effects. These extraneous sources of variation could have easily been minimized under a controlled experimental environment, highly unlikely under an on-farm setting.

\section{Practical Aspects of Maize Stover Improvement and Feeding On-farm}

Since maize stover is available on most of the farms in the locality, some specific aspects of it were explored during the study. These aspects, which involved maize stover improvement and feeding, were found practical by all participating farmers with no major implications on labour for both men and women. However, the aspects involving the storage and chopping of maize stover were initially found impractical. It was only after group evaluation of the results that practical methods of storing maize stover were agreed upon. Having overcome the initial limitations, the farmers main concern was the extent to 
which the improved stover utilization technology impacted on the dairy sub-enterprise in relation to the quantity and quality of feed available. The farmer perceptions revealed the underlying importance of maize stover in addressing the feed constraint problem during the dry season.

\section{Maize Stover Storage and Processing}

In the present study it was noted that only 10 per cent of participating households had ideal storage facilities for maize stover. Most farmers generally heaped the material under trees and on fence lines. Different methods for efficient storage of maize stover were discussed and demonstrated to farmers who agreed to adopt them. Some of the methods had been practiced by farmers but without any technical consideration to the potential devastating effects rains, sunny weather and termite could have on the nutritive value of the stover. Among the methods recommended where relatively low losses in nutrients or termite attack may be expected include storage of baled material or stacking in heaps on raised platforms inside sheltered sheds. With minor modifications, areas within the standard zero-grazing units above the resting ground for the cattle were exploited for storage by some of the farmers.

Due to the drudgery involved in chopping the stover into smaller particles, most of the farmers offered the same in the relatively long form; however, animals selected against it leading to poor utilisation. To ease this drudgery some farmers used forage choppers or other devices like the locally developed ("jua kali") hand chopper.

\section{Gender Considerations and benefits}

The present study embraced the role of gender in the up-take and adoption of the feed technologies being tested on-farm. This was from the realisation that because of the nature of the division of labour on smallscale mixed farms gender perspectives may influence adoption rates to a greater extent than technical and economic responses. From the onset, discussions and activity profiles done during the PRA study revealed that although the routine farm activities and domestic chores of men and women varied, both had similar interests in and access to the dairy enterprise. It was, however, established that women were increasingly being involved in the management of the enterprise as male members of the family migrated to towns in search of salaried jobs. This meant that women worked for long hours in a wide portfolio of activities related to the management of the dairy enterprise in addition to the domestic chores. Despite the burden, women farmers were just as much willing as men to participate in the research as they considered any interventions that would help in mitigating the feed shortage problem beneficial by saving the time wasted in fending for livestock feed.

During the planning stages of the research project, it was recognised that the new technologies within the project would enhance feed supply but at the expense of some additional labour. This was expected to influence participation of women farmers since the technology involved 'cutting, carrying and chopping' Napier grass, and chopping maize stover and mixing it thoroughly with molasses. However, during discussions with both male and female participants at the onset of the project and at the ex-post project evaluation, it was found that $95 \%$ of both the men and women farmers did not consider labour a limiting factor. Although the proposed research interventions were appropriate and responsive to a commonly perceived problem, a consideration of the potential participation and subsequent adoption of the technologies on the basis of such pre-conceived limitations such as labour, without seeking group opinion would have ruled out active participation by women. This would have underscored the contribution that women would have made to this research. In a situation where women have interest, as found in the current study, they cannot be ignored since their non-participation could have seriously affected the research output. These findings justified the participation, from the beginning, of both men and women.

Some of the positive project attributes beneficial to women included: a) availability of feed locally which reduced the cost and more so the burden to search for forage often done outside the farms; $b$ ) the increased income meant women will be able to meet some of the domestic obligations, further improving their livelihood base; c) access to more milk enabled women to meet the nutritional requirements of the family, particularly for the nutritionally challenged children. Appropriate technological innovations, like those developed in the present project that to some extent reduce the work burden on women farmers or improve their access to productive resources and services can have far reaching effects on agricultural productivity and lift women farmers out of the vicious circle of misery, poverty and under-development in rural Kenya. Due to the great role women play, their participation in research should continuously be encouraged.

\section{Economic Analysis of Feed Technologies On-farm}

The on-farm trial recognized the importance of economic viability as an important criteria of assessing new technologies and management practices. New technologies are expected to either increase returns (e.g. increased production), reduce costs or positively impact both. The project embraced the fact that economic analysis allows the comparison of technologies which may have mixed, often different impact. For instance, 
one feed additive might increase total milk production while another could reduce the cost of producing milk.

In the present study, primary and secondary data were used in the economic appraisal of the technologies on offer. However, most of the data was derived from activities undertaken by the project staff and the farmers. The sampling frame included participating and non-participating farmers in the targeted areas. A total of 38 farmers (respondents) were interviewed (19 of them were participants in the on-farm feeding project; the other 19 were non-participating farmers).

The economic tools used in this study to quantify the cost and returns to the dairy feed technologies under investigation included Gross margins (GM), Benefit Cost (B:C) ratio, Net returns (NR) per unit output (GM/output), NR per unit income (GM/Income) and NR per unit of labour input (GM/Manday). The values for these economic indices are as presented in Table 4.

Table 4. Profit analysis of the dry season feeding'

\begin{tabular}{lll}
\hline Factor & $\begin{array}{l}\text { Participating } \\
\text { Farmers }\end{array}$ & $\begin{array}{l}\text { Non-participating } \\
\text { Farmers }\end{array}$ \\
\hline Gross Margin (Kshs/Cow/3Month) & 4418 & 1852 \\
Benefit:Cost Ratio & 2 & 1.21 \\
NR* per unit output (GM/Output) & 5 & 2 \\
NR per unit income (GM/Income) & 0.29 & 0.21 \\
NR per unit of labour input (GM/Manday) & 200 & 145 \\
Production costs (Kshs/litre of milk) & 8.7 & 15 \\
Milk production/cow/month (litres) & 295 & 283 \\
\hline
\end{tabular}

${ }^{*} \mathrm{NR}=$ net returns.

'These values were averaged over the diets fed during the study.

The GM for the 3 months dry season (December, 1998 to February, 1999) is positive for both participating and non-participating farmers, clearly guaranteeing the viability of the dairy enterprise in the study areas. However, the GM of participating farmers is higher by $58 \%$ over that of the farmers who were not participating in the project. This implies that farmers who were not practising the technologies were losing Kshs 855 per month during the dry season. The benefit cost $(B: C)$ ratio further demonstrated that "test' farmers received Kshs 2 (compared to 1.21 for non-participating farmers) for every shilling invested in the new feed technologies.

The Net returns per unit output of milk and income also favoured the participating farmers. The GM for participating (P) and non-participating (NP) farmers was Ksh 5 and 2, respectively for each litre of milk produced. Likewise, the NR/income i.e. returns as profit for every shilling earned was 0.29 and 0.21 for $P$ and NP farmers, respectively. The returns per unit labour were also higher by $28 \%$ for $P$ than NP farmers. Interestingly the NP farmers incurred a higher cost to produce a litre of milk (Ksh 15) compared to almost a $50 \%$ reduction in the cost of producing for $P$ farmers. This could be attributed to the fact that the "test" farmers mostly relied on cheap and locally available feed resources, mostly crop residues. Additionally, considerable amounts of Napier grass, usually expensive in the dry season, was replaced by maize stover which, currently is poorly priced. The use of the inexpensive, abundant and unexploited molasses further increased intakes of the crop residues lowering the dependence of green material during the dry season. This decreased considerably the cost of feeding the dairy cow in the dry season.

Overall the economic analyses revealed that the dry season feed technologies being 'tested' were viable and sustainable within the farming systems in the study locations.

\section{Adaptability and Impact of the On-farm Research Methodology}

Based on the household socio-economic impact of the research there is eminent potential of the technologies to have implications on dairy development in Vihiga District and in many parts of western Kenya since maize is widely grown on small scale farms. The general consideration within the methodology framework in-built within the on-farm project was to involve the farmers in all the stages of the research process. The traditional research approach that has been employed in the recent decades during the implementation of several research activities marginalized the involvement of farmers; the research tended to be "technology driven" rather than 'need or demand driven". The lack of close co-ordination between the researcher, extensionist further limited the ability to assist farmers most effectively. It has been recognised that this 'top-bottom' approach that has been used in the past led to the poor adoption of technologies being disseminated (Ndubi, 1998). This scenario was avoided in the current project by adopting a participatory methodological approach that involved the farmers, researchers and extensionists at all stages of the research process. 
The involvement of farmers in the identification of their problems and in the setting of relevant research interventions improved their responsiveness to the technology under 'testing' and consequently to its wider adoption. An essential element in the research methodology was the opportunity it offered for feedback information to research and its potential transformation into the mainstream extension activities. Furthermore, integrating women in the research process, as adopted in the project, overcame the problem of women under-representation; thus women had greater access to technical information through training in-built in the project and from continued dialogue with the researchers. Such information was found to increase their knowledge and skills not only within the domain of the dairy cattle production sub-sector, but also in other complementary agricultural production activities. This, in several cases, led to the diversification of farming activities and therefore to the overall systems improvement. The developed methodology could therefore greatly enhance farmer participation in research development and dissemination of proven technologies while further cementing the linkages between farmers, researchers and extensionists. There is eminent potential for institutionalising the methodology and enhancing its application in future livestock research.

\section{CONCLUSION}

The on-farm research project was designed to involve farmers in developing technologies for improving availability of feed to smallholder farms by mainly utilizing Napier grass with varying proportions of the available crop residues such as maize stover, banana leaves/stems. The main impact of the findings of the research, at least at household level, included an increased range of feed resources that are within reach of the smallholder farmers by exploiting the crop residues and improved methods of Napier grass establishment for increased dry matter yields. The improved feed availability benefited both male and female farmers primarily in terms of increased milk for sale to earn extra income or for domestic consumption, as well as the generation of extra manure. However, women appeared to benefit more as they were increasingly involved in managing the dairy cows and had extra needs in terms of meeting nutritional requirements of the families.

Primarily, the technology on the use of crop residues as livestock feed is likely to have significant contribution to the development of dairy production in mixed crop-livestock systems in Kenya. Secondarily, the research methodology employed, which allowed for the active participation of farmers and most importantly, the enlistment of gender perceptions, was catalytic to the uptake of the technologies on offer. It has great potential for institutionalisation.

\section{ACKNOWLEDGEMENT}

The author wishes to acknowledge the assistance by the Rockefeller Foundation for supporting this research. I would also like to thank the Director KARI for hosting me during the conduct of this study. The assistance of livestock research staff from the Regional Research Centre (RRC), Kakamega is greatly appreciated. Last but not least, I would like to thank the livestock extension staff of the Ministry of Agriculture and Rural Development in Vihiga District for their invaluable support during the actual on-farm trials.

\section{REFRENCES}

Abate, A., B.H. Dzowela and J.A. Kategile. 1991. Intensive animal feeding practices for optimum feed utilisation. Future of Livestock Industries in Eastern and Southern Africa. Proc. of Workshop at Kadona Ranch Hotel, Zimbabwe, 20-23, July. ILCA, Addis ababa, Ethiopia. Pp.9

Kevelenge, J.E. 1978. The nutritive value of four farm products commonly fed to dairy cattle by small-scale farmers. Msc Thesis, University of Nairobi.

MacMillan, S. 1996. Improving the rumen: helping the animals get the most out of their feed livestock. Livestock Research for Development. International Livestock Research Institute (ILRI) Neswsletter 12. No. 2 ISSN 1024-3437.Pp 5.

Methu, J.N. Owen, A.N. Abate, D.M. Mwangi and J.C. Tanner. 1997. Smallholder dairying in the Central highlands: Practices in the utilisation of maize stover as fed resource. $5^{\text {th }}$ KARI Scientific Conference, 14-16 October, 1996, Kaptagat Road, Loresho, Nairobi, Kenya. Pp. 243.

NDDP. 1990. The National Dairy Development Project, Ministry of Agriculture and Livestock Development and Marketing Report, Nairobi.

Ndubi, J. 1998. Importance of gender considerations in participatory approaches to agricultural research: Experiences from KARI Embu. In: (Eds. Curry, J., Kooijman, M. and Recke, H.) Institutionalizing gender considerations and analyses into a National Agricultural Research System: Experiences from Kenya. P 111.

Renard, C. (ed.). 1997. Crop residues in sustainable mixed crop/livestock farming systems. CAB International. Wallington, U.K. 